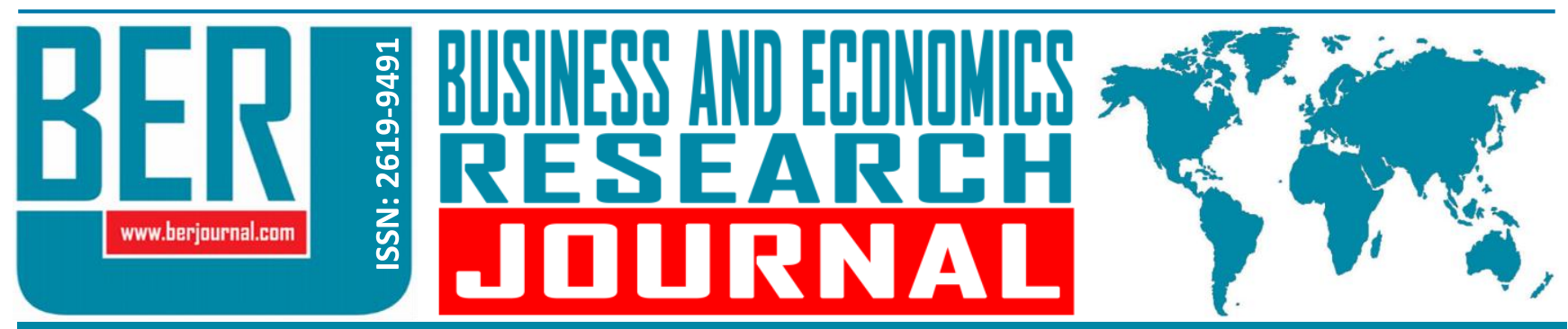

Business and Economics Research Journal Vol. 11, No. 2, 2020, pp. 397-411 doi: 10.20409/berj.2020.257

\section{Yabancı Yatırımcı Sahipliği Oranındaki Değişimin Getiri, Volatilite ve Likidite Üzerindeki Etkisi: BIST GYO Sektörü İçin Panel Veri Analizi}

Anahtar Sözcükler: Yabancı Yatırımcılar, Taban Genişlemesi, Fiyat Baskısı, GYO, BIST

JEL: F32, G14, G16

$\begin{array}{ll}\text { Geliş } & : 19 \text { Şubat 2020 } \\ \text { Düzeltme } & : \text { 11 Mart 2020 } \\ \text { Kabul } & : \text { 27 Mart 2020 } \\ & \text { Tür }\end{array}$

Keywords: Foreign Investors, Base Broadening, Price Pressure, REIT, BIST

JEL: F32, G14, G16

Received : 19 February 2020 Revised : 11 March 2020 Accepted : 27 March 2020

Type : Research

Cite this article as: Kilic, S., Delikanli, I. U., \& Alp, A. (2020). Yabancı yatıımcı sahipliği oranındaki değişimin getiri, volatilite ve likidite üzerindeki etkisi: BIST GYO sektörü için panel veri analizi. Business and Economics Research Journal, 11(2), 397-411.

The current issue and archive of this Journal is available at: www.berjournal.com

Prof., PhD., Altınbaş University, Faculty of Business Administration, Department of Business Administration, Istanbul, Turkiye, saim.kilic@altinbas.edu.tr (ORCID ID: 0000-0001-7180-2201)

b PhD., Altınbaş University, Faculty of Business Administration, Department of Business Administration, Istanbul, Turkiye, ugur2ihsan@yahoo.com (ORCID ID: 0000-0001-8955-5413)

Prof., PhD., TOBB Economy and Technology University, Faculty of Economics and Administration, Department of Business Administration, Ankara, Turkiye, aalp@etu.edu.tr (ORCID ID: 0000-0003-1469-5408) 


\section{Giriş}

Yabanc yatırımcılar, yerel yatırımcı tabanının zayıflığı nedeniyle sermaye birikimi yeterli olmayan gelişmekte olan ülke piyasaları için oldukça önemlidir. Yabancı yatırımcı girişi bir taraftan ülkenin sermaye açığının kapatılmasını sağlarken diğer taraftan da yatırım yapılan pay senedinin fiyatı, volatilitesi ve likiditesi üzerinden tüm pay piyasasını etkiler.

Yabancı pay sahipliğinin pay senedinin getirisi, volatilitesi ve likiditesi üzerindeki etkisi tartışmalı bir konu olup, (i) taban genişlemesi (base broadening) hipotezi, (ii) fiyat baskısı (price pressure) hipotezi ve (iii) geribildirim ticareti (feedback trading) hipotezi şeklinde geliştirilmiş üç önemli hipotez bulunmaktadır.

Merton (1987) tarafından ortaya atılan taban genişlemesi hipotezine göre; yabancı portföy yatırımlarının artması piyasadaki mevcut yatıımcı tabanının genişlemesine, yabancı tabanındaki genişlemenin artan işlemlerle birlikte likiditede artışa, likidite artışının risk paylaşımı yaratarak risk primlerinde azalışa, risk primlerinin azalması da sermayenin maliyetini düşürerek pay senetlerinin fiyatında bir artışa yol açmaktadır. Bu hipotezde özetle; yabancı pay sahipliği oranındaki artışın uzun vadede likiditeyi artırdığı, riski (volatiliteyi) azalttığı ve getiriyi yükselttiği öne sürülmektedir. Clark ve Berko (1996) Meksika piyasasında, Dahlquist ve Roberstson (2004) İsveç piyasasında, Richards (2005) altı adet Asya piyasasında, Reis, Meuer ve Silva (2010) Brezilya piyasasında, Samarakoon (2009) Sri Lanka piyasasında, Okuyan ve Erbaykal (2011), Avcı (2015), Sönmezer (2016) ve Yıldız (2017) Türkiye piyasasında taban genişleme hipotezinin geçerli olduğuna dair bulgulara ulaşılmıştır. Adabağ ve Ornelas (2006) bu hipotezin Türkiye için kısa vadede geçerli olduğu sonucuna ulaşmıştır.

Warther (1995) tarafından geliştirilen fiyat baskısı hipotezi; özellikle gelişmekte olan ülkelere gelen büyük hacimli yabancı portföy yatırımlarının, bu piyasaların sığ olması nedeniyle fiyatlar üzerinde baskı yaratarak yapay bir fiyat artışına neden olacağını ancak bu etkinin belli bir süre sonra ortadan kalkarak fiyatların eski seviyelerine döneceğini ileri sürmektedir. Bu hipotez temelde; likidite, risk ve fiyatlardaki olumlu etkinin geçici olduğunu belirtmektedir. Clark ve Berko (1996) Meksika piyasasında, Adabağ ve Ornelas (2006) ile Sönmezer (2016) Türkiye piyasasında bu hipotezin tümüyle reddedildiğini ortaya koyarken, Baklacı (2009) Türkiye'deki bazı pay senetleri için bu hipotezin desteklendiğini tespit etmiştir.

Geri bildirim hipotezine göre ise yerli yatırımcılara nazaran daha az bilgiye sahip olan yabancı yatırımcılar, pay piyasasındaki son fiyat bilgisine bakarak değerlendirme yapmakta ve iki farklı strateji ile işlem gerçekleştirmektedir (Doğukanlı ve Çetenek, 2008). Pozitif geri bildirim stratejisinde; piyasadaki yükseliş trendini takiben alım yapılırken, piyasadaki düşüş trendini takiben satış yapılır. Buna karşılık, negatif geribildirim stratejisinde; piyasada yükseliş trendi varken satış, düşüş trendi varken alım gerçekleştirilir. Dolayısıyla, yabancı yatırımcılar, bu stratejilerden hangisini gerçekleştirirse pay senedinin getirisinin yönü de ona göre şekillenir (Sönmezer, 2016). Choe, Kho ve Stulz (1999) Güney Kore piyasasında, Grinblatt ve Keloharju (2000) Finlandiya piyasasında, Karolyi (2001) Japonya piyasasında, Chen (2002) Tayvan piyasasında, Dahlquist ve Roberstson (2004) İsveç piyasasında, Richard (2005) altı Asya ülke piyasasında, Reis, Meuer ve Silva (2010) Brezilya piyasasında, Sönmezer (2016) Türkiye piyasasında pozitif geri bildirim stratejisini destekleyen bulgulara ulaşırken, Adabağ ve Ornelas (2006) ve Akar (2007) Türkiye için negatif geri bildirim stratejisinin geçerli olduğu yönünde kanıtlar bulmuştur.

Öte yandan, uygulamacıların da bu hipotezler arasında özellikle taban genişlemesi hipotezini destekler yönde görüşler beyan ettikleri görülmektedir. Dünya Borsalar Federasyonu tarafından yayımlanan rapora (WFE, 2019: 8) göre, Borsa İstanbul'un da içinde yer aldığı gelişmekte olan ülke borsalarının kurumsal olarak, yabancı yatırımcıların piyasalarına olumlu etkisi olduğunu; yabancı yatırımcılar sayesinde ülkeye sermaye girişi ile birlikte piyasanın geliştiğini; yabancı işlemlerinin yerli yatırımcı işlemlerini dengeleme görevi gördüğünü ve fiyat istikrarına katkıda bulunduğunu belirtmektedirler.

Literatüre bakıldığında, Baklacı (2009)'nın yirmi adet pay senedi bazlı araştırması hariç, bugüne kadarki çalışmalarda söz konusu hipotezlerin esas olarak piyasayı temsil eden çeşitli endeksler kullanılarak gerçekleştirildiği görülmektedir. Bu çalışmalarda; net yabancı portföy girişi, yabancı alım satım işlemleri ve yapancı pay sahipliği oranı gibi değişkenler ile çeşitli piyasa endekslerinin getirisi, volatilitesi ve likiditesi 
arasındaki ilişkiler regresyon, Granger nedensellik testi, eş bütünleşme, VAR, ARDL sınır testi, Etki-Tepki analizi gibi yöntemler kullanılarak test edilmiştir. Ancak, piyasanın geneli için yapılan araştırma sonuçları hem sektör hem de pay senedi bazında farklılık gösterebilecektir. Piyasaya yeni yabancı girişi olmadığı halde, piyasadaki mevcut sektörlerin ve/veya pay senetlerinin yabancı pay sahipliğinde değişimler meydana gelmektedir. Bu değişimlerin etkisini ölçmenin de anılan hipotezlerin geçerliliğini test etmede önemli olduğu değerlendirilmektedir. Bu amaçla, belli bir sektöre dahil pay senetlerinde meydana gelen önemli nitelikteki yabancı pay sahipliği değişimlerinden panel veri oluşturmak suretiyle bu hipotezlerin sınanabileceği düşünülmektedir.

Borsa İstanbul'daki (BIST) sektör endeksleri incelendiğinde, Borsa i̇stanbul'da işlem gören gayrimenkul yatırım ortaklığı (GYO) statüsündeki şirketlerin pay senetlerinin son dönemde \%60'lara varan oranlarda iskontolu olarak işlem görmekte olduğu ve BIST GYO Endeksinin BIST 100 Endeksinden olumsuz yönde ayrıştığı gözlenmektedir. Bir pay senedinin borsada iskontolu işlem görmesi, ilgili şirket için borsada oluşan piyasa değerinin o şirketin net aktif değerinin altında olması anlamına gelmektedir. Tablo 1'de yer alan sahiplik ve elde tutma bilgileri, yabancı yatırımcıların hem GYO pay senetlerindeki sahiplik oranının hem de elde tutma süresinin azaldığını göstermektedir. Zira, 2010 yılında ortalama olarak \%27,15 olan yabancı yatırımcı sahiplik oranı ve 323 gün olan elde tutma süresi zamanla azalarak 2018 yılı sonu itibariyle sırasıyla $\% 17,78$ 'ye ve 237 güne gerilemiştir. Dolayısıyla taban genişlemesi hipotezinin geçerliliğinin BIST'de işlem gören GYO'lar için araştırılması halinde, GYO pay senedi fiyatlarındaki iskontosunun yabancı pay sahipliğindeki azalmadan kaynaklanıp kaynaklanmadığı sorusuna bir cevap geliştirilebileceği düşünülmektedir.

Tablo 1. GYO Pay Senetlerinde Ortalama Elde Tutma Süresi ve Yabancı Oran

\begin{tabular}{cccc}
\hline & \multicolumn{2}{c}{ Elde Tutma Süresi (Gün) } & $\begin{array}{c}\text { Yabancı Yatırımcının Pay } \\
\text { Oranı }\end{array}$ \\
\cline { 2 - 3 } Yıl & Yerli Yatırımcı & Yabancı Yatırımcı & $27,15 \%$ \\
2010 & 24 & 323 & $22,59 \%$ \\
2011 & 23 & 183 & $20,34 \%$ \\
2012 & 51 & 295 & $16,70 \%$ \\
2013 & 53 & 188 & $14,66 \%$ \\
2014 & 72 & 252 & $15,18 \%$ \\
2015 & 92 & 258 & $14,19 \%$ \\
2016 & 86 & 261 & $14,09 \%$ \\
2017 & 45 & 192 & $14,78 \%$ \\
2018 & 70 & 178 & $\mathbf{1 7 , 7 4 \%}$ \\
\hline Genel Ortalama & $\mathbf{5 7}$ & $\mathbf{2 3 7}$ & \\
\hline
\end{tabular}

Kaynak: Merkezi Kayıt Kuruluşu

Bu çerçevede, çalışmanın amacı, uygulamacılar arasında daha çok kabul gören ve ampirik olarak da desteklenen taban genişlemesi hipotezinin Borsa İstanbul GYO sektörü için panel veri analizi yöntemiyle test edilmesi ve böylece yabancı sahipliğindeki azalmanın GYO sektörü pay senetlerinin BIST'de iskontolu işlem görmesinde rol oynayıp oynamadığının ortaya konulmasıdır. Çalışmanın; güncelliği, farklı bir yöntemle yapılması ve GYO sektörünü özel olarak incelemesi nedenleriyle literatüre katkı sağlayacağı düşünülmüştür.

Çalışma beş bölümden oluşmaktadır. Bu bölümünden sonraki ikinci bölümde, ilgili literatür açıklanmıştır. Üçüncü bölümde, araştırmanın kapsamı, veri seti ve metodolojisi verilmiştir. Dördüncü bölümde, araştırma sonucunda elde edilen bulgular belirtilmiş ve bu bulgularla ilgili değerlendirmeler yapılmıştır. Son bölümde de ulaşılan sonuçlar ile öneriler özetlenmiştir. 


\section{Literatür Taraması}

Literatürde bir önceki bölümde verilen hipotezlerin bazılarını veya tamamını çeşitli ülke piyasaları için test eden çok sayıda çalışma mevcuttur.

Clark ve Berko (1996)'nun Ocak 1989- Mart 1996 dönemini kapsayan çalışmasında, Meksika pay piyasasında net yabancı portföy girişlerindeki \%1'lik değişimin pay senetleri fiyatında aynı yönde \%13'lük değişime yol açtığı ortaya konularak taban genişlemesi hipotezinin geçerli olduğuna dair bulgulara ulaşılmış, ancak fiyat baskısı hipotezi ile geri bildirim hipotezini destekleyen bir sonuca varılmamıştır.

Dahlquist ve Roberstson (2004), İsveç piyasası için yaptıkları çalışmada, yabancıların işlemleri ile piyasanın getirisi arasında güçlü bir korelasyon olduğunu, yabancı yatırımcıların alımlarındaki artışın şirketlerin sermaye maliyetlerini yaklaşık \%2 düşürerek pay senetleri fiyatlarında kalıcı bir etkiye neden olduğunu, dolayısıyla da taban genişlemesi hipotezinin varlığını tespit etmişlerdir. Bu çalışmada ayrıca net yatırımcı alımlarının pay senedi getirilerinin geçmiş değerlerinden pozitif yönde etkilendiği ortaya konularak pozitif geri bildirime ilişkin bulgular da elde edilmiştir.

Richards (2005) Asya'nın altı ülke piyasası için günlük verileri kullanarak gerçekleştirdiği çalışmasında, bu piyasalarda yatırımcıların geçmiş getirilere bakarak pozitif geri bildirim davranışında bulundukları, yabancı yatırımcı işlemlerinin geçmişte tahmin edilenden daha yüksek oranda pay fiyatını olumlu yönde etkilediği, yabancıların gelişmekte olan piyasalardaki etkisinin önceki araştırmalarınkinden daha büyük (\%38) çıktığı sonucuna ulaşılmıştır.

Choe, Kho ve Stulz (1999), Güney Kore hisse senedi piyasasında yabancı yatırımcıların pozitif geribildirim stratejisi uyguladıklarını ancak ekonomik kriz döneminde böyle bir sergilenmediğini saptamıştır. Aynı çalışmada, yabancı işlemlerin piyasadaki istikrarı bozduğuna dair bir kanıt da elde edilememiştir. Chen (2002) Tayvan hisse senedi piyasasında yabancı yatırımcıların pozitif geri besleme davranışı gösterdiklerini bulmuştur. Karolyi (2001) Japonya piyasası için yabancıların pozitif geri bildirim hipotezini destekleyen güçlü kanitlar elde etmiştir.

Grinblatt ve Keloharju (2000), Finlandiya piyasasında yabancı yatırımcıların geçmişte kazandıran pay senetlerini satın alma, geçmişte kaybettiren pay senetlerini ise satma eğilimi gösterdiklerini ortaya koyarak pozitif geri bildirim bulgusuna ulaşmıştır.

Swanson ve Lin (2003), sekiz gelişmekte olan ülke için uluslararası fon akımı ile piyasa getirisi arasındaki ilişkiyi geri bildirim hipotezi ve uluslararası fon akımının bilgi içerip içermediği açılarından araştırmış, araştırma sonucunda uluslararası fon akımına ilişkin bilginin pay senedi üzerindeki etkisinin pozitif geri bildirim hipotezinden daha güçlü olduğu bulgusuna ulaşılmıştır.

Reis, Meuer ve Silva (2010), Brezilya'da 1995-2005 döneminde pay senedi getirileri ile yabancı yatırımlar arasındaki ilişkileri incelemiş olup, inceleme sonucunda yabancı portföy yatırımlarının bu dönemdeki getiriyi önemli oranda olumlu yönde etkilediği, bu iki değişken arasında yüksek korelasyon bulunduğu, yabancı portföy yatırımlarının döviz kuru, dünyadaki endeks değişimleri ve ülke riski değişkenleriyle birlikte pay piyasasındaki getirinin yüzde \%73'ünü açıklama gücüne sahip olduğu, ayrıca piyasada pozitif geri bildirimin rol oynadığı tespitlerini yapmıştır.

Sri Lanka pay piyasasında gerçekleşen günlük alım satım işlemleri ile hisse getirisi arasındaki ilişkilerin yatırımcı türü bazında inceleyen Samarakoon (2009) çalışmasında; kriz dönemleri hariç olmak üzere, hem yerli hem de yabancı yatırımcıların alım satım işlemleri ile geçmiş piyasa getirileri arasında pozitif ilişki bulunduğu, yerli kurumsal ve yabancı bireysel yatırımcıların alımlarının gelecekte daha yüksek getirilere yol açmasına karşın yerli bireysel yatırımcıların alımlarının nispeten daha düşük getirilere sebep olduğu, yabancı kurumsal yatırımcı alımlarının gelecekteki getirileri etkilemediği, yabancı yatıımcı satışlarının yerli yatırımcıların satışlarının aksine gelecekte daha yüksek getirilere yol açtığı bulgularına ulaşıımıştır.

Adabağ ve Ornelas (2006)'ın çalışmasında, Borsa İstanbul'da 1997-2004 döneminde net yabancı portföy girişi ile BIST Tüm Endeksi arasındaki ilişki araştırılmış, taban genişlemesi hipotezinin uzun vadede 
değil kısa vadede geçerli olduğu, fiyat baskısı ve pozitif geribildirim hipotezlerinin hiç desteklenemediği, negatif geribildirim hipotezinin ise çok zayıf olmakla birlikte desteklendiği bulgusu elde edilmiştir.

Akar (2007), Borsa İstanbul'da Ocak 1997-Mart 2007 döneminde net yabancı işlem hacmi ile BIST 100 endeksinin getirisi arasındaki nedensellik ilişkisini Granger nedensellik testiyle ve pozitif geri besleme hipotezini etki tepki analizi yardımıyla test etmiş olup, çalışma sonucunda hisse senedi getirilerinden net yabancı işlem hacmine doğru tek yönlü nedensellik olduğunu ve yabancıların negatif geri beslemeye uygun davranış gösterdiklerini ortaya koymuştur.

Doğukanlı ve Çetenek (2008), Borsa İstanbul'da Şubat 1997-Aralık 2006 döneminde aylık verilerden yola çıkarak VAR, Granger ve Etki-Tepki analizlerini kullanmak suretiyle gerçekleştirdiği çalışmasında, pay senedi getirisi ile yabancı portföy yatırımları arasında nedensellik ilişkisi olduğunu, yabancı yatırımcıların fiyat değişikliklerini dikkate alarak alım veya satım kararı aldıklarını göstermiştir.

Baklacı (2009), Borsa İstanbul'da 2005-2008 döneminde 20 adet pay senedindeki yabancı yatırımcı etkisini inceleyerek, fiyat baskısı hipotezinin söz konusu pay senetlerinin bir bölümünde gözlemlendiği sonucuna ulaşmıştır.

Okuyan ve Erbaykal (2011), Borsa İstanbul için 1997-2009 dönemini kapsayan ARDL modelini kullanarak yaptığı çalışmada, yabancı işlemleri ile pay senedi getirileri arasında uzun dönemde pozitif bir ilişkinin bulunduğu ancak bu ilişkinin kısa dönemde anlamlı olmadığı görülmüştür. Taban genişlemesi hipotezinin uzun vadede desteklendiği belirtilmiştir.

Avcı (2015)'nın çalışmasında ise, 2003-2014 döneminde, yabancı yatırımcıların işlemleri ile BIST 100 Endeksinin getirisi arasındaki ilişki incelenmiş, iki değişken arasında uzun dönemli bir ilişki bulunduğu ve bu ilişkinin yabancı yatırımcı işlemlerinden borsa getirisine doğru bir nedensellik içerdiği tespit edilmiştir.

Sönmezer (2016)'in Borsa İstanbul için 2005-2009 dönemini kapsayan çalışmasında da, BIST 30 Endeksinin getirisi ile hem piyasa değerine hem de yatırımcı sayısına göre hesaplanan yabancı oranları arasındaki ilişki incelenerek söz konusu hipotezler test edilmiştir. Çalışma sonucunda, taban genişlemesi hipotezini destekleyecek şekilde yabancı yatırımcı oranlarındaki değişimin istatistiksel olarak BIST 30 Endeksindeki değişimi önemli ve anlamlı ölçüde açıkladığı, fiyat baskısı hipotezinin tümüyle reddedildiği, pozitif geribildirim hipotezinin ise güçlü şekilde kabul edildiği bulgularına ulaşılmıştır.

Yıldız (2017), Borsa İstanbul için 2006-2015 dönemini içeren çalışmasında, şirket seviyesinde yabancı fonların sahiplik oranı ile hisse senedi getiri oynaklığı arasında negatif bir ilişki gözlendiği ve dolayısıyla da işlem yapan yabancı fonların piyasanın fiyat istikrarına katkıda bulunduğu sonucuna varmıştır.

\section{Araştırmanın Veri ve Metodolojisi}

Araştırmada, BIST'de 2010-2018 döneminde işlem gören GYO'ların pay senetlerindeki yabancı pay sahipliği oranında meydana gelen ani değişimin söz konusu pay senetlerinin getirisine, volatilitesine ve likiditesine etkisi panel veri analizi yoluyla incelenmek suretiyle taban genişlemesi hipotezinin geçerliliği ampirik olarak test edilmiştir.

Tablo 1'e göre yabancıların GYO pay senetlerini son 10 yılda ortalama olarak 237 gün (yaklaşık olarak sekiz ay) elde tuttukları dikkate alınarak, araştırmanın amaçladığı etki ölçümü ve hipotez testi, yabancı pay sahipliği değişiminin gerçekleştiği tarihten sonraki sekiz ay için yapılmıştır. Zira yabancılar ortalama olarak her sekiz ayda bir ellerindeki pay senetlerini satmaktadırlar. Dolayısıyla, yabancıların pay sahipliğinin etkisi elde tuttukları süre içinde ölçülebilirse daha anlamlı olabilir. Ayrıca, sekiz aylık dönemler dikkate alındığında, panel veri analizini yapmaya yetecek kadar örneklem de elde edilebilmiştir. Eğer söz konusu sekiz ayın tamamına yakınında yabancı payı oranındaki değişime bağlı olarak pay senetlerinin likiditesinde ve getirisinde aynı yönde, volatilitesinde farklı yönde istatistiksel olarak anlamlı değişimler varsa taban genişlemesi hipotezinin geçerli olduğuna dair bulgudan bahsedilebileceği düşünülmüştür. 

Analizi

Tablo 2. Çalışmanın Örneklemini Oluşturan GYO Pay Senetlerine ilişkin Bilgiler

\begin{tabular}{|c|c|c|c|c|c|c|c|}
\hline Sayı & $\begin{array}{l}\text { GYO } \\
\text { Adı }\end{array}$ & $\begin{array}{l}\text { Yabancı Oran } \\
\text { Değişim Tarihi }\end{array}$ & $\begin{array}{l}\text { Yabancı Oranda } \\
\text { Puansal Değişim }\end{array}$ & Sayı & $\begin{array}{l}\text { GYO } \\
\text { AdI }\end{array}$ & $\begin{array}{l}\text { Yabancı Oran } \\
\text { Değişim Tarihi }\end{array}$ & $\begin{array}{l}\text { Yabancı Oranda } \\
\text { Puansal Değişim }\end{array}$ \\
\hline 1 & Akfen & Mart 2014 & $-\% 11$ & 17 & Pera & Nisan 2013 & $-\% 28$ \\
\hline 2 & Akfen & Ağustos 2016 & $-\% 11$ & 18 & Reysaş & Temmuz 2011 & $\% 18$ \\
\hline 3 & Akfen & Temmuz 2017 & $\% 13$ & 19 & Reysaş & Ekim 2012 & $-\% 24$ \\
\hline 4 & Alarko & Mart 2013 & $-\% 20$ & 20 & Reysaş & Haziran 2014 & $\% 15$ \\
\hline 5 & Emlak & Ağustos 2012 & $\% 17$ & 21 & Saf & Temmuz 2011 & $-\% 7$ \\
\hline 6 & Emlak & Mart 2017 & $-\% 6$ & 22 & Sinpaş & Mart 2011 & $-\% 16$ \\
\hline 7 & Emlak & Ocak 2018 & $-\% 9$ & 23 & Sinpaş & Aralık 2011 & $-\% 7$ \\
\hline 8 & Halk & Ocak 2015 & $\% 5$ & 24 & Sinpaş & Eylül 2013 & $\% 12$ \\
\hline 9 & İş & Nisan 2011 & $-\% 5$ & 25 & Sinpaş & Haziran 2014 & $-\% 14$ \\
\hline 10 & Kiler & Nisan 2012 & $-\% 5$ & 26 & Torunlar & Aralık 2012 & $\% 9$ \\
\hline 11 & Kiler & Ocak 2013 & $\% 5$ & 27 & Torunlar & Mayıs 2016 & $\% 5$ \\
\hline 12 & Kiler & Haziran 2017 & $\% 11$ & 28 & Torunlar & Eylül 2017 & $\% 6$ \\
\hline 13 & Martı & Haziran 2012 & $-\% 14$ & 29 & TSKB & Mart 2011 & $-\% 5$ \\
\hline 14 & Özak & Mayıs 2018 & $\% 6$ & 30 & TSKB & Ocak 2012 & $-\% 5$ \\
\hline 15 & Özderici & Ocak 2011 & $\% 6$ & 31 & YK Koray & Nisan 2011 & $-\% 18$ \\
\hline 16 & Pera & Ağustos 2011 & $\% 9$ & 32 & Yeşil & Ocak 2011 & $-\% 16$ \\
\hline
\end{tabular}

Araştırmanın Tablo 2'de verilen örneklemi şu şekilde tespit edilmiştir. Öncelikle, 2010-2018 döneminde faaliyette bulunan 35 GYO'ya ilişkin olarak ay sonları itibariyle hesaplanan yabancı pay sahipliği oranı, halka açıkıı oranı ve halka açıkıı oranı çcindeki yabancı pay sahipliği oranı bilgileri Merkezi Kayıt Kuruluşu'ndan elde edilmiştir. Yabancı pay sahipliğindeki değişimlerden hangilerinin kapsama alınacağı konusunda üç temel kriter belirlenmiştir. Birinci kriter, önemlilik derecesini göstermek üzere, yabancı pay sahipliğinde en az \%5 puan değişim meydana gelmesidir. Araştırmanın amacı yabancı pay sahipliğindeki her bir değişimin etkisini değil, ani ve önemli nitelikteki pay değişimlerinin etkisini ölçmektir. Sermaye piyasası düzenlemelerinde pay sahipliğindeki \%5 değişim önemli bilgi olarak kabul edilip kamuya açıklama yükümlülüğü getirildiğinden, paralel olması bakımından bu araştırmada da aynı oran benimsenmiştir. íkinci kriter, değişimin gerçekleştiği aydan önceki sekiz aylık dönemde ve sonraki sekiz aylık dönemde yabancı pay sahipliği oranının önemli değişikliğe uğramadan istikrarlı seyretmesidir. Böylelikle, araştırmanın amacına uygun olarak sekiz aylık etkiyi görmek mümkün olacaktır. Üçüncü kriter ise, yabancı pay sahipliği oranındaki değişimin, halka açıkık oranında meydana gelen değişimden kaynaklanmamasıdır. Aksi halde, ortaya çıkan etkinin halka açıklık oranının değişmesinden mi yoksa yabancı pay sahipliği oranının değişmesinden mi kaynaklandığının ayırt edilmesi mümkün olmayacaktır. Bu kriterler kullanılarak toplam 17 GYO statüsündeki şirket için dokuz yıllık dönemin değişik zaman dilimlerinde dengesiz (unbalanced) panel veri niteliğindeki 32 adet gözlemi içeren bir örneklem oluşturulmuştur.

Çalışmada kullanılan değişkenler ve hesaplanma biçimleri Tablo 3'de gösterilmektedir. Panel regresyonun bağımsız değişkeni, Yabancı Pay Oranıdır. YOYD olarak kısaltılan bu değişkeni temsil etmek üzere, iki dönem arasında halka açıklık oranı içindeki yabancı pay sahipliği oranında meydana gelen yüzde değişim esas alınmıştır. Bunun için, öncelikle, değişim öncesi sekiz aylık dönem ve değişim sonrası sekiz aylık dönem için halka açıklık oranı içindeki ortalama yabancı pay sahipliği oranları hesaplanmış, ardından bu döneme ilişkin oranlar arasındaki değişim oranının yüzdesi bulunmuştur. Panle regresyonun bağımlı değişkenleri Anormal Getiri, Volatilite ve Likiditedir. Anormal Getiri (AR) hesaplaması için, önce ilgili GYO pay senedinin ve BIST 100 endeksinin günlük getirileri bulunmuş; ardından literatürde (Kadıoğlu, Telçeken ve Öcal, 2015; Liljeblom, 1989; Martikainen ve diğerleri, 1993; Aydoğan ve Muradoğlu, 1998; Travlosve diğerleri, 2001) önerildiği üzere küçük piyasalar için yapılan analizlerde daha iyi sonuçlar veren "piyasaya göre düzeltilmiş model" çerçevesinde pay senedinin günlük getirilerinden endeksin günlük getirileri çıkarılmak suretiyle günlük anormal getiriler elde edilmiş; sonra da elde edilen günlük anormal getiriler aylık bazda 
toplanmıştır. Volatilite değişkeni (OVOL), pay senedi için hesaplanan günlük getirilerin aylık bazda standart sapmasının alınması suretiyle bulunmuştur. Likidite değişkeninin (LOGOSOZ) göstergesi olarak, pay alım satımı sonucunda piyasada gerçekleşen aylık ortalama sözleşme sayısı esas alınmıştır. Aylık ortalama sözleşme sayısı, hesaplamanın yapıldığı aya ilişkin günlük sözleşme sayılarının aritmetik ortalamaları alınmak suretiyle bulunmuştur. Büyük değerlere sahip olan bu sayıları analize elverişli hale getirmek için logaritmaları alınmıştır.

Tablo 3. Değişkenler ve Hesaplanma Şekilleri

\begin{tabular}{|c|c|c|c|}
\hline Değişken & Kısaltması & Hesaplama Yöntemi & Kaynak \\
\hline $\begin{array}{l}\text { Yabancı Pay } \\
\text { Oranı }\end{array}$ & YOYD & $\begin{array}{l}\text { Sonraki sekiz ayın Yabancı Pay Oranı/Halka Açıklık Oranı ortalamasında } \\
\text { önceki sekiz aya göre meydana gelen yüzdesel değişim }\end{array}$ & $\begin{array}{l}\text { Merkezi Kayıt } \\
\text { Kuruluşu }\end{array}$ \\
\hline Anormal Getiri & AR & $\begin{array}{l}\text { Ay bazında, GYO pay senedinin günlük getirisi ile BIST } 100 \text { endeksinin } \\
\text { günlük getirisi arasındaki farkların toplamı }\end{array}$ & Borsa İstanbul \\
\hline Volatilite & OVOL & Ay bazında, GYO pay senetlerinin günlük getirilerinin standart sapması & Borsa İstanbul \\
\hline Likidite & LOGOSOZ & $\begin{array}{l}\text { Ay bazında, GYO pay senedi piyasasında gerçekleşen günlük } \\
\text { sözleşmelerin aritmetik ortalamalarının logaritması }\end{array}$ & Borsa İstanbul \\
\hline
\end{tabular}

Değişkenler bu şekilde belirlendikten sonra; yabancı pay sahipliği oranı ile getiri, volatilite ve likidite arasındaki ilişkiyi ortaya koymak amacıyla aşağıda sırasıyla verilen (1), (2) ve (3) numaralı panel regresyon modelleri oluşturulmuştur:

$$
\begin{aligned}
& \mathrm{AR}_{\mathrm{it}}=\propto+\beta \text { YOYD }_{i t}+\mathrm{u}_{\mathrm{it}} \\
& \text { OVOL }_{\mathrm{it}}=\propto+\beta \text { YOYD }_{\mathrm{it}}+\mathrm{u}_{\mathrm{it}} \\
& \text { LOGOSOZ }_{\mathrm{it}}=\propto+\beta \text { YOYD }_{\mathrm{it}}+\mathrm{u}_{\mathrm{it}}
\end{aligned}
$$

Eşitliklerdeki $\propto$, modelin sabit değerini; $\beta$, modeldeki açıklayııı değişkenin katsayısını; $u_{i t}=\mu_{i}+\varepsilon_{i t}$, panelin genel hata terimini; i alt indisi, yatay kesit birim (GYO) sayısını; $\mathrm{t}$ alt indisi, zaman dönemini; $\mu$, $\mathrm{i}$ birimine ait birim etkisini; $\varepsilon_{i t}$, i biriminin hata terimini ifade etmektedir.

Söz konusu üç panel regresyon modelinin her biri sekiz ay için ayrı ayrı tekrarlanmak suretiyle toplamda 24 adet regresyon tahmini yapılmıştır.

Ancak, panel veri analizi yapılmadan önce bu analize ilişkin varsayımların test edilerek oluşturulan veri setinin ve kurulan modellerin analize uygunluğunun sınanması gerekir. Bu kapsamda sınanması gereken varsayımlar şunlardır:

- Yatay kesitler arasında bağımlılık olmaması varsayımı,

- Serilerde birim kök olmaması (serilerin durağan olması) varsayımı,

- Değişen varyans (heteroskedasite) bulunmaması varsayımı,

- Otokorelasyon bulunmaması varsayımı.

Yatay kesitler arasında bağımlılık olmaması varsayımı, paneli oluşturan yatay kesit birimlerinin (her bir GYO verisinin) birbirinden bağımsız olmalarını, dolayısıyla da bir yatay kesit biriminde meydana gelen değişmenin diğer yatay kesit birimlerini etkilememesi anlamına gelmektedir. Seriler arasında yatay kesit bağımlılığının varlığını test eden çok sayıda test bulunmakla birlikte, yatay kesit boyutunun zaman boyutundan büyük olduğu (N>T) durumlarda Pesaran CD testi kullanılmaktadır (Topaloğlu, 2018). Ancak söz konusu testin önemli varsayımlarından biri, her bir yatay kesit için en az üç dönem $\left(T_{i j}>2\right)$ bulunması 
zorunluluğudur (Pesaran, 2004). Araştırmada kullanılan dengesiz panel veri niteliğindeki veri setinde $N=17$ ve yatay kesitlerdeki on bir adet birim için $T \leq 2$ olup, test koşulu sağlamadığından anılan test uygulanamamaktadır. Ancak, her ne kadar söz konusu testin uygulanmaması araştırma açısından bir kısıt ise de iki nedenden dolayı yatay kesit bağımlılığının olmadığı varsayımında bulunmak mümkün görünmektedir. Illk olarak, analizde kullanılan yatay kesit verisinin neredeyse tamamına yakını, Tablo 2'den de görüleceği üzere, dokuz yıllık zaman diliminde birbirlerinden farklı dönemdeki verileri kapsamaktadır. İkincisi, Pesaran (2004: 1), yatay kesit boyutu $(\mathrm{N})$ yeterince yüksek olan panellerde kesitlerin bağımsız olduğu varsayımının büyük ölçüde doğru olduğunu ifade etmektedir. Dolayısıyla, bu kısıtlar altında, çalışmada yatay kesit birimlerindeki değişimlerin birbirinden bağımsız olduğu varsayımı yapılmıştır.

Serilerde birim kök bulunmaması varsayımı, zaman serilerinin kullanıldığı regresyon modellerinde her bir değişkene ait serinin durağan olmasını gerektirir. Araştırmada kullanılan verinin hem zaman serisi niteliğinde olmaması hem de panelin dengesiz olması dikkate alınarak, verilerin tek tek durağanlık testine tabi tutulması yerine, regresyonların kesişmeli eşitlikleri için Levin, Li ve Chu (2002), Im, Pesaran ve Shin (2003), Augmented Dicky-Fuller (1979) ve Phillip ve Perron (1998) grup birim kök testleri gerçekleştirilmiştir.

Panel veri analizi sonuçlarının geçerli olabilmesi için, standart hatalara ilişkin varyansların sabit olması gerekir. Çalışmada, değişen varyans sorununun mevcut olmaması varsayımı, panel regresyonun, Beck ve Katz (1995) tarafından geliştirilen Period SUR (PCSE) yöntemi kullanılarak düzeltilmiş standart hatalarla tahmin edilmesi suretiyle sağlanmıştır.

Panel veri analizinin diğer önemli varsayımı olan standart hatalar arasında otokorelasyon bulunmaması varsayımı ise Wooldridge (2002) tarafından uygulanan yöntemle sınanmıştır. Bu amaçla, öncelikle hata terimleri ile bir dönem gecikmeli hata terimleri arasında regresyon yapılarak bir katsayı tahmin edilmiş, daha sonra da "Tahmin edilen katsayı -0,5 değerine eşit ise hata teriminin birbirini izleyen değerleri arasında otokorelasyon yoktur" şeklindeki hipotez Wald Testi yardımıyla sınanmıştır. Hipotezin kabul edilmesi, otokorelasyon sorununun bulunmadığı anlamına gelmektedir.

Ayrıca, her bir regresyon analizi öncesinde, rassal etkili (random effect) modelin mi yoksa sabit etkili (fixed effect) modelin mi uygun olduğunu belirlemek amacıyla da çalışmada Hausman testi uygulanmıştır.

Araştırmadaki analizler ve testler Eviews paket programı yardımıyla gerçekleştirilmiştir.

\section{Bulgular ve Tartışma}

Panel regresyon analizine esas teşkil eden verilerin durağan olup olmadığını tespit etmek amacıyla gerçekleştirilen Levin, Li ve Chu (2002), Im, Pesaran ve Shin (2003), Augmented Dicky-Fuller (1979) ve Phillip ve Perron (1998) grup birim kök test sonuçları Ek.1'de verilmiştir. Verilerin durağan olduğu, bir başka ifade ile birim kök içermediği görülmüştür.

Araştırma kapsamında 24 adet panel regresyon analizinin her biri için gerçekleştirilen Hausman test sonuçlarına ilişkin özet bilgiler Ek 2'de yer almaktadır. Bu sonuçlara göre, tahmini yapılan 24 regresyonun 9'u için rassal etkili model, $15^{\prime} \mathrm{i}$ için sabit etkili model seçilip bir sonraki aşamada uygulanmıştır.

Yabancı yatırımcı oranındaki değişimin pay senetlerinin getirisinde, volatilitesinde ve likiditesinde önemli bir rol oynayıp oynamadığını ortaya koymak amacıyla 2010-2018 döneminde seçilen 17 adet GYO'ya ait toplam 32 gözlem kullanılarak, yabancı pay sahipliği oranındaki değişimin olduğu tarihten sonraki sekiz ay için (1), (2) ve (3) numaralı eşitlikler çerçevesinde gerçekleştirilen regresyon tahmin sonuçları Tablo 4, 5 ve 6 'da özetlenmiştir.

Tablo 4'de verilen değerlerden de görüleceği gibi, yabancı payı oranı ile getiri arasında ikinci ve üçüncü aylardaki ilişki \%99 güvenirlik düzeyinde istatistiksel olarak anlamlı çıkmıştır. Söz konusu iki ayda yabancı payı oranı ile anormal getiri arasında pozitif bir ilişki mevcut olup, $\mathrm{R}^{2}$ değerlerine göre yabancı pay sahipliği oranının anormal getiriyi açıklama gücü sırasıyla $\% 73$ ve $\% 64$ olarak gözlemlenmiştir. Katsayılar \%3,97 ve $\% 2,27$ olarak tahmin edilmiştir. Başka bir deyişle, GYO'ların yabancı pay sahipliği oranında meydana gelen \%1’lik artış (azalış), ilgili pay senedinin getirisinde ikinci ayda \%3,97, üçüncü ayda \%2,27 oranında artışa 
(azalışa) yol açmaktadır. Diğer aylarda ise yabancı payı oranı ile getiri arasında istatistiksel olarak anlamlı bir ilişki bulunamamıştır.

Tablo 4. Yabancı Pay Sahipliği Oranı ile Getiri Arasında Dengesiz Panel Regresyon Sonuçları

\begin{tabular}{lcccccccc}
\hline $\begin{array}{c}\text { Zaman } \\
\text { (Ay) }\end{array}$ & $\begin{array}{c}\text { Bağımlı } \\
\text { Değişken }\end{array}$ & $\begin{array}{c}\text { Bağımsız } \\
\text { Değişken }\end{array}$ & Etki & $\begin{array}{c}\text { Sabit } \\
\text { Terim }\end{array}$ & Katsayı & $\mathbf{R}^{2}$ & $\begin{array}{c}\text { t- } \\
\text { Istatistiği }\end{array}$ & Prob. \\
\hline 1. Ay & AR1 & YOYD & Rassal & $-0,0206$ & 0,00356 & 0,02 & 0,8065 & 0,4263 \\
2. Ay & AR2 & YOYD & Sabit & $-0,0277$ & 0,03970 & 0,73 & 4,0664 & $0,0012^{*}$ \\
3. Ay & AR3 & YOYD & Sabit & $-0,0083$ & 0,02274 & 0,64 & 3,7543 & $0,0021^{*}$ \\
4. Ay & AR4 & YOYD & Rassal & $-0,0290$ & 0,00440 & 0,01 & 0,6705 & 0,5077 \\
5. Ay & AR5 & YOYD & Rassal & $-0,0239$ & $-0,00564$ & 0,04 & $-1,2877$ & 0,2077 \\
6. Ay & AR6 & YOYD & Rassal & $-0,0279$ & 0,00043 & 0,00 & 0,1084 & 0,9144 \\
7. Ay & AR7 & YOYD & Rassal & 0,0011 & $-0,00487$ & 0,03 & $-1,2210$ & 0,2316 \\
8. Ay & AR8 & YOYD & Rassal & $-0,0139$ & $-0,00369$ & 0,02 & $-0,7921$ & 0,4345 \\
\hline
\end{tabular}

*\%1 seviyesinde anlamlıdır.

Değişen varyansa karşı Period SUR (PCSE) yöntemi ile standart hataların düzeltilmesi yoluyla tahmin gerçekleştirilmiştir.

Yabancı pay sahipliği oranı ile volatilite arasındaki panel regresyon sonuçlarının yer aldığı Tablo 5'e göre üçüncü, dördüncü ve beşinci aylarda \%99 güvenirlik düzeyinde pozitif yönde anlamlı bir ilişki mevcuttur. Bu aylarda yabancı pay sahipliği oranının volatiliteyi açıklama gücü sırasıyla \%90, \%74, \%61 olarak gerçekleşmiştir. Tahmin edilen katsayılar, getiri için hesaplanan katsayılar kadar yüksek olmayıp \%0,25, \%0,29 ve $\% 0,42$ şeklindedir. Genel olarak düşük katsayıların tahmin edildiği diğer aylarda ise, yabancı pay sahipliği oranı ile volatilite arasında anlamlı bir ilişki yoktur.

Tablo 5. Yabancı Pay Sahipliği Oranı ile Volatilite Arasında Dengesiz Panel Regresyon Sonuçları

\begin{tabular}{ccccccccc}
\hline $\begin{array}{c}\text { Zaman } \\
\text { (Ay) }\end{array}$ & $\begin{array}{c}\text { Bağımlı } \\
\text { Değişken }\end{array}$ & $\begin{array}{c}\text { Bağımsız } \\
\text { Değişken }\end{array}$ & Etki & $\begin{array}{c}\text { Sabit } \\
\text { Terim }\end{array}$ & Katsayı & $\mathbf{R}^{\mathbf{2}}$ & $\begin{array}{c}\text { t- } \\
\text { İstatistiği }\end{array}$ & Prob. \\
\hline 1. Ay & OVOL1 & YOYD & Rassal & 0,0190 & 0,00062 & 0,03 & 0,9892 & 0,3345 \\
2. Ay & OVOL2 & YOYD & Rassal & 0,0196 & 0,00124 & 0,05 & 1,2913 & 0,2064 \\
3. Ay & OVOL3 & YOYD & Sabit & 0,0177 & 0,00250 & 0,90 & 5,9501 & $0,0000^{*}$ \\
4. Ay & OVOL4 & YOYD & Sabit & 0,0192 & 0,00293 & 0,74 & 4,2314 & $0,0008^{*}$ \\
5. Ay & OVOL5 & YOYD & Sabit & 0,0014 & 0,00428 & 0,61 & 3,6842 & $0,0025^{*}$ \\
6. Ay & OVOL6 & YOYD & Rassal & 0,0191 & $-0,00048$ & 0,02 & $-0,8192$ & 0,4191 \\
7. Ay & OVOL7 & YOYD & Rassal & 0,0199 & 0,00058 & 0,03 & 1,0114 & 0,3199 \\
8. Ay & OVOL8 & YOYD & Rassal & 0,0216 & $-0,00025$ & 0,01 & $-0,4801$ & 0,6346 \\
\hline
\end{tabular}

*\%1 seviyesinde anlamlıdır.

Değişen varyansa karşı Period SUR (PCSE) yöntemi ile standart hataların düzeltilmesi yoluyla tahmin gerçekleştirilmiştir.

Yabancı pay sahipliği oranı ile likidite arasındaki regresyon sonuçları da (Tablo 6), volatilite ilişkisine benzer şekilde üçüncü, dördüncü ve beşinci aylarda istatistiksel olarak pozitif anlamlı bir ilişkinin olduğunu göstermektedir. Yabancı pay sahipliği oranının likiditeyi açıklama gücünü ölçen $\mathrm{R}^{2}$ değerleri de sırasıyla \%87, \%80 ve \%75 olarak tahmin edilmiştir. Hesaplanan katsayılara bakıldığında, GYO'ların yabancı pay sahipliği oranındaki \%1'lik bir değişim, GYO pay piyasasının likiditesinde üçüncü ayda $\% 10,63$, dördüncü ayda \%13,59 ve beşinci ayda \%9,08 oranında aynı yönde değişime sebep olmaktadır. Diğer aylar için yabancı oranı ile likidite arasında anlamlı bir ilişki mevut değildir. 
Yabancı Yatırımcı Sahipliği Oranındaki Değişimin Getiri, Volatilite ve Likidite Üzerindeki Etkisi: BIST GYO Sektörü Için Panel Veri Analizi

Tablo 6. Yabancı Pay Sahipliği Oranı ile Likidite Arasında Dengesiz Panel Regresyon Sonuçları

\begin{tabular}{ccccccccc}
\hline $\begin{array}{c}\text { Zaman } \\
\text { (Ay) }\end{array}$ & $\begin{array}{c}\text { Bağımlı } \\
\text { Değişken }\end{array}$ & $\begin{array}{c}\text { Bağımsız } \\
\text { Değişken }\end{array}$ & Etki & $\begin{array}{c}\text { Sabit } \\
\text { Terim }\end{array}$ & Katsayı & $\mathbf{R}^{\mathbf{2}}$ & t-istatistiği & Prob. \\
\hline 1. Ay & LOGOSOZ1 & YOYD & Rassal & 2,8611 & 0,04515 & 0,09 & 1,5311 & 0,1362 \\
2. Ay & LOGOSOZ2 & YOYD & Rassal & 2,8023 & 0,04667 & 0,08 & 1,5199 & 0,1390 \\
3. Ay & LOGOSOZ3 & YOYD & Sabit & 2,8179 & 0,10639 & 0,87 & 4,6125 & $0,0004^{*}$ \\
4. Ay & LOGOSOZ4 & YOYD & Sabit & 2,7692 & 0,13592 & 0,80 & 4,6270 & $0,0004^{*}$ \\
5. Ay & LOGOSOZ5 & YOYD & Sabit & 2,7988 & 0,09089 & 0,79 & 2,8269 & $0,0134^{* *}$ \\
6. Ay & LOGOSOZ6 & YOYD & Sabit & 2,7708 & 0,07617 & 0,75 & 1,9226 & 0,0751 \\
7. Ay & LOGOSOZ7 & YOYD & Rassal & 2,8166 & $-0,01350$ & 0,01 & $-0,4708$ & 0,6412 \\
8. Ay & LOGOSOZ8 & YOYD & Rassal & 2,8834 & $-0,03372$ & 0,05 & $-1,2404$ & 0,2244 \\
\hline
\end{tabular}

$* \% 1, * * \% 5$ seviyesinde anlamlıdır.

Değişen varyansa karşı Period SUR (PCSE) yöntemi ile standart hataların düzeltilmesi yoluyla tahmin gerçekleştirilmiştir.

Regresyon sonucunda anlamlı ilişki tespit edilen AR2, AR3, OVAL3, OVAL4, OVAL5, LOGOSOZ3, LOGOSOZ4 ve LOGOSOZ5 modellerinde standart hatalar değişen varyansa karşı Period SUR (PCSE) metodu ile standart hatalar düzeltilerek tahmin yapıldığından panel veri analizine ilişkin değişen varyans varsayımı bakımından bir sorun bulunmamaktadır.

Otokorelasyon varsayımı için Wooldridge (2002) yöntemiyle Walde testi yapılmış olup, Tablo 7'de yer alan sonuçlardan görüleceği üzere, analizde otokorelasyon sorunu da mevcut değildir. Dolayısıyla, tespit edilen anlamlı ilişkilerin geçerli olduğu anlaşılmaktadır.

Tablo 7. Otokorelasyon Varsayımına İlişkin Test İstatistikleri

\begin{tabular}{lccc}
\hline \multirow{2}{*}{ Model } & Hata (-1) için & \multicolumn{2}{c}{ Wald Testi } \\
\cline { 3 - 4 } & Hesaplanan Katsayılar & t- istatistiği & Prob. \\
\hline AR2 & $-0,69114$ & $-0,6820$ & 0,5064 \\
AR3 & $-0,58979$ & $-0,4784$ & 0,6397 \\
OVAL3 & $-0,79840$ & $-1,3164$ & 0,2092 \\
OVAL4 & $-0,80453$ & $-1,5535$ & 0,1426 \\
OVAL5 & $-0,20870$ & 1,4650 & 0,1650 \\
LOGOSOZ3 & $-0,24915$ & 1,1030 & 0,2886 \\
LOGOSOZ4 & $-0,47495$ & 0,1020 & 0,9202 \\
LOGOSOZ5 & $-0,44450$ & 0,2240 & 0,8260 \\
\hline
\end{tabular}

Wald Testi için $\mathrm{H}_{\circ}$ Hipotezi: Katsayı Değeri $=-0,05$

Yukarıda özetlenen regresyon analizi bulguları birlikte değerlendirildiğinde, ilk olarak, yabancı pay sahipliği oranında ciddi bir değişim meydana geldiğinde BIST'de işlem gören GYO pay senetlerinde getirinin, volatilitenin ve likiditenin kısa vadede aynı yönde değişim gösterdiği, daha sonra bu etkinin tamamen ortadan kaybolduğu anlaşılmaktadır. Analizde yer alan yabancı pay sahipliği oranı değişiminin GYO'ların pay piyasasında 2010-2018 döneminde gerçekleşen ani nitelikteki ciddi değişimler olduğu dikkate alındığında, yatay kesitlerin bağımsız olduğu varsayımı altında, uzun vadede taban genişlemesi hipotezinin geçerli olmadığı bulgusuna ulaşmak mümkündür. Zira, taban genişlemesi hipotezinin tam anlamıyla desteklenebilmesi için, modelimize göre, GYO'larda yabancı pay sahipliği değişiminden sonraki sekiz ayın tamamına yakınında getiride pozitif etki söz konusu olmalıdır. Kaldı ki, volatilitedeki etki de hipotezde iddia edilenin aksi yöndedir. Dolayısıyla, taban genişlemesi hipotezi likidite ve getiri açısından kısa vadede geçerli olsa bile, uzun vadede geçerli olduğuna dair bulguya ulaşılamamıştır. Bulgumuz, Adabag ve Ornelas (2006)'ın çalışmasının sonuçları ile uyumlu; Yıldız (2017)'ın çalışmasının bulgularıyla ise uyumsuzdur. 
Yabancı pay sahipliği oranındaki ciddi değişime rağmen, değişimi takip eden ilk ayda getiri ve likidite üzerinde anlamlı bir etkinin olmamasının, kısmen de olsa 2010-2018 döneminde BiST tarafından uygulanan taraf bilgisinin gösterilmemesi (kör havuz) düzenlemesi ile açılanabileceği düşünülmektedir. BisT, özellikle yabancı yatırımcılarla çalışan aracı kurumların gerçekleşen işlemlerde taraf olarak gösterilmesinin "Bu pay senedinde yabancılar işlem yapıyor" algısı yaratarak yatırımcıların alım satım kararlarını yanıltıcı bir şekilde etkilediği ve piyasayı bozduğu gerekçesiyle, 08.10.2010 tarihinden itibaren geçerli olmak üzere borsada gerçekleşen işlemlerde taraf bilgisini (hangi aracı kurumun işlem yaptığını) göstermemeye başlamıştır. Bu uygulama, 02.05.2018 tarihine kadar devam etmiştir. Araştırma dönemi ile örtüşen bu dönemde taraf bilgisinin gösterilmemesi, yabancılar için işlemi gerçekleştiren aracı kurumların bilgisinin de gösterilmemesi anlamına geldiğinden, piyasanın yabancıların pay sahipliği hakkında zamanında bilgi sahibi olmalarını zorlaştırmıştır. Bunun da piyasanın gecikmeli olarak yabancı pay sahipliği değişimlerine tepki vermesine yol açtığı görüşü taşınmaktadır.

Öte yandan, volatilite ve likidite etkisinin, getirinin etkisinden bir ay daha fazla sürdüğü görülmektedir. Bunun bir nedeni, yine taraf bilgisinin gösterilmemesi olabilir. Zira, piyasadaki asimetrik bilgi dağılımı ve yabancı pay sahipliği oranlarına ilişkin farklı söylentiler nedeniyle, likidite ve volatilite daha fazla etkilenmiş olabilir. Başka bir neden de likidite ve volatilitedeki değişimin, getirinin de kesin değişeceği anlamına gelmemesidir.

Son olarak, tahmin edilen getiri, volatilite ve likidite katsayılarının değerlerine bakıldığında, kısa dönemde ortaya çıkan yabancı pay sahipliği oranı etkisinin ölçek olarak en çok likiditede (aylık ortalama $\% 11,3$ ) ve getiride (aylık ortalama \%3,12 olmakla birlikte piyasaya göre düzeltildiği dikkate alındığında) olduğu anlaşılmaktadır. Volatilitedeki etki ise ölçek olarak oldukça düşük olup, teoriye göre yabancı yatırımcıların volatiliteyi azaltması beklendiğinden, volatilite artışının yüksek çıkmaması bu açıdan anlaşıır bulunmuştur.

\section{Sonuç}

Yabancı yatırımcıların özellikle gelişmekte olan piyasalara etkisi literatürde en çok incelenen konulardan birisidir. Yabancı yatırımcılar sayesinde piyasaya sermaye girişi olduğu konusunda herkes hemfikir iken, yabancı yatırımcıların sahiplik oranı değişikliğinin ve piyasada gerçekleştirdikleri işlemlerin pay senetlerinin getirisi, volatilitesi ve likiditesi üzerindeki etkisinin yönü, uzunluğu ve bu etkinin gerekçeleri konusunda farklı hipotezler mevcuttur. Dünyanın değişik piyasaları için yapılan ampirik çalışmalarda da değişik bulgulara ulaşılmıştır.

Türkiye açısından da konu farklı olmayıp, Borsa İstanbul'da işlem gören GYO sektöründeki yabancı pay sahipliği etkisinin incelenmemiş olduğu ve BIST GYO sektörü endeksinin yabancı pay sahipliğindeki azalma ile birlikte BIST 100 endeksinden olumsuz yönde ayrıştığı dikkate alınarak, literatürde en çok kabul gören ve ampirik olarak da desteklenen taban genişlemesi hipotezinin geçerliliğinin GYO sektörü pay senetleri için güncel veri ile test edilmesi ve bu testlerde farklı yöntem ve analizlerin kullanılması suretiyle literatüre katkı sağlanması amaçlanmıştır.

Bu kapsamda, 2010-2018 döneminde pay senetleri Borsa İstanbul'da işlem gören 35 adet GYO statüsündeki şirket araştırma kapsamına alınmış, bunlardan 17 'sine ilişkin olarak bu dönemin değişik zaman dilimlerinde meydana gelen ani ve ciddi nitelikteki yabancı pay sahipliği değişimlerinden 32 adet örneklem niteliğinde panel veri oluşturulmuştur. Bu değişimlerden sonraki sekiz aylık dönem için aylık bazda anormal getiri, sözleşme sayısı ve standart sapma hesaplanmış, böylece panel regresyon analizi yardımıyla da her ay için yabancı pay sahipliğindeki değişim ile getiri, likidite ve volatilite arasındaki ilişki ayrı ayrı ampirik olarak test edilmiştir.

Araştırma sonuçlarına göre; yabancı pay sahipliğindeki değişim ile getiri, likidite ve volatilite arasında sadece kısa vade için aynı yönde istatistiksel olarak anlamlı bir ilişki olduğu tespit edilmiştir. Ancak, bir önceki bölümde verilen diğer bilgilerle birlikte değerlendirildiğinde, taban genişlemesi hipotezinin BIST GYO sektörü için teoride öngörüldüğünün aksine kalıcı olmadığı (uzun vadede geçerli olmadığı) bulgusuna ulaşılmıştır. Bu durum ayrıca, GYO pay senedi fiyatlarında gözlenen iskontonun tek başına yabancı işlemlerindeki azalma ile açıklanamayacă̆ı sonucunu ortaya koymaktadır. 
Bu sonuçlardan yola çıkarak, taban genişleme hipotezinin ancak kısa vadede geçerli olduğunu veyahut diğer hipotezlerden fiyat baskısı hipotezinin geçerli olabileceği ileri sürülebilir. Ancak, burada dikkat edilmesi gereken husus, BIST GYO sektörü için bu hipotezlerin geçerliliğine yol açan nedenlerin teoriden farklı olmasıdır. Şöyle ki, taban genişlemesi hipotezinde, yabancı pay sahipliği oranındaki artışın yabancı yatırımcı tabanını artıracă̆ı, likiditeyi yükselteceği, riski azaltacağı ve böylece fiyatları yükselteceği öne sürülmektedir. Fiyat baskısı hipotezinde ise sığ olan piyasaya yabancı yatırımcıların gelmesi ile birlikte artan işlem hacmi ile fiyatların yapay olarak yükseleceği, belli bir süre sonra fiyatların eski seviyelerine döneceği öngörülmektedir. Burada ise kısa vadede tabanın genişlemesi ve/veya fiyatların ve likiditenin yapay olarak yükselmesi, bizatihi yabancı yatırımcıların kendilerinden değil, yabancı yatırımcıların piyasaya girdiği bilgisi nedeniyle yerli yatırımcının pay senetlerine ilgi göstermesinden kaynaklandığı düşünülmektedir. Başka bir deyişle, yabancı yatırımcının pay sahipliği "bilgi içeren" (information content) bir olgu olup, yatırımcı tabanı bu bilginin piyasada bir şekilde ortaya çıkması ile birlikte yerli yatırımcıların piyasaya ilgi göstermesiyle genişlemekte ve yerli yatırımcı işlemleri ile fiyat yükselmektedir. Bu tespit, Swanson ve Lin (2003) çalışması ile paralellik arz etmektedir. Kaldı ki, yabancı pay sahipliğinde değişime yol açan yabancı işlemleri, yerli yatırımcıların işlemlerine nazaran daha büyük hacimlidir. Dolayısıyla, yabancı yatırımcıdan kalıcı bir likidite beklememek gerekir. Yabancılar, piyasada işlemini gerçekleştirmekte ve uzun süre park etmektedirler. Devamında asıl işlemi yapanlar, yabancıların pay sahipliğinde değişim olduğunu öğrenen yerli yatırımcılardır. Bu yorumumuz, yabancı pay sahipliği oranındaki artışla birlikte az da olsa volatilitenin neden yükseldiğini açıkladığı gibi, taraf göstermeme düzenlemesinin mantığı ve sonuçları ile de uyum içerisindedir.

Bununla birlikte, bu araştırmada ulaştığımız sonuçların, Borsa İstanbul için yapılacak başka çalışmalarla da test edilmesi yararlı olacaktır. Özellikle pay senedi bazında tek tek uzun vadeli ilişkiyi, nedenselliği ve eş bütünleşmeyi araştıran çalışmalar yapılmak suretiyle bu konuda daha net bulgulara ulaşılabileceği düşünülmektedir. Ayrıca, bugüne kadar daha çok endeks bazlı yapılan çalışmaların sonuçlarının her sektör için geçerli olmayabileceği dikkate alınarak, bu çalışmada olduğu gibi sektör bazında araştırmalar yapılması da önerilmektedir.

\section{Beyan ve Açıklamalar (Disclosure Statements)}

1. Bu çalışmanın yazarları, araştırma ve yayın etiği ilkelerine uyduklarını kabul etmektedirler (The authors of this article are admitted that they complied with the principles of research and publication ethics).

2. Yazarlar tarafından herhangi bir çıkar çatışması beyan edilmemiştir (No potential conflict of interest was reported by the authors).

3. Bu çalışma, intihal tarama programı kullanılarak intihal taramasından geçirilmiştir (This article was screened for potential plagiarism using a plagiarism screening program).

\section{Kaynaklar}

Adabag, M. C., \& Ornelas, J. R. H. (2004). Behavior and effects of foreign investors on Istanbul Stock Exchange. Available at SSRN: https://ssrn.com/abstract=656442

Akar, C. (2007). Yabancılar Türkiye'de pozitif geri besleme hipotezine uygun davranışlar gösterirler mi? iMKB Dergisi, 10(39), 61-67.

Allen, F., \& Gale, D. (1991). Limited market participation and the volatility of asset prices. American Economic Review, $84,933-955$.

Avcı, Ö. B. (2015). Effect of foreign investor transactions on stock market returns. Hacettepe University Journal of Economics and Administrative Sciences, 33(4), 29-38.

Aydoğan, K., \& Muradoğlu, G. (1998). Do markets learn from experience? Price reaction to stock dividends in the Turkish market. Applied Financial Economics, 8, 41-49.

Baklaci, H. F. (2009). iMKB'de yabancı yatırımcı işlemleri ve getiri etkileşimi üzerine ampirik bir çalışma. IMKB Dergisi, 11(42), 37-59. 
Chen, Y. (2002). Domestic investors' herding behavior in reaction to foreign trading. National Taiwan University International Conference in Finance, 1-20.

Choe, H., Kho, B., \& Stulz, R. M. (1999). Do foreign investors destabilize stock markets? The Korean experience in 1997. Journal of Financial Economics, 54, 227-264.

Clark, J., \& Berko, E. (1996). Foreign investment fluctuations and emerging market stock returns: The case of Mexico. Federal Reserve Bank of New York Research Paper No.9635, 1-35.

Dahlquist, M., \& Robertsson, G. (2004). A note on foreigners' trading and price effects across firms. Journal of Banking and Finance, 28(3), 615-632.

Dickey, D. A., \& Fuller, W. A. (1979). Autoregressive time series with a unit root. Journal of the American Statistical Association, 74, 427-431.

Doğukanlı, H., \& Çetenek, E. H. (2008). Yabancı portföy yatırımları ile hisse senedi getirisi arasındaki ilişki: iMKB'de sınama. Çukurova Üniversitesi IiBF Dergisi, 12(2), 37-57.

Errunza, V., \& Losqo, E. (1989). Capital flow controls, international asset pricing and investors' welfare: A multicountryframework. Journal of Finance, 44(4), 1025-1037.

Harigs, K. (1995). The internationalization of emerging equity markets: Domestic market development or retardation? University of Illinois Working Paper Series.

Im, K. S., Pesaran, M. H., \& Shin, Y. (2003). Testing for unitroots in heterogeneous panels. Journal of Econometrics, 115(1), 53-74.

Grinblatt, M., \& Keloharju, M. (2000). The investment behavior and performance of various investor types: A study of Finland's unique data set. Journal of Financial Economics, 55, 43-67.

Karolyi, G. A. (2001). Did the Asian financial crisis scare foreign investors out of Japan? Unpublished Working Paper, The Ohio State University, Columbus, $\mathrm{OH}$.

Kadıoğlu, E., Telçeken, N., \& Öcal, N. (2015). Market reaction to dividend announcement: Evidence from Turkish stock market. International Business Research, 8(9), 83-95.

Levin, A., Lin, C. F., \& Chu, J. (2002). Unitroottests in panel data: Asymptotic and finite-sample properties. Journal of Econometrics, 108(1), 1-24.

Liljeblom, E. (1989). The informational impact of announcements of stock dividends and stock splits. Journal of Business Finance and Accounting, 16, 681-697.

Martikainen, T., Rothovlus, T., \& Yli-Olli, P. (1993). On the individual and incremental information content of accrual earnings, cash flowsand cash dividends in the Finnish stock market. European Journal of Operational Research, 68, 318-333.

Merton, R. C. (1987). A simple model of capital market equilibrium with incomplete information. The Journal of Finance, 42(3), 483-510.

Okuyan, H. A., \& Erbaykal, E. (2011). IMKB'de yabancı işlemleri ve hisse senedi getirileri ilişkisi. Doğuş Üniversitesi Dergisi, 12(2), 256-264.

Pagano, M. (1989). Endogenous market thinness and stock price volatility. Review of Economic Studies, 56, $269-287$.

Pesaran, M. H. (2004). General diagnostic tests for cross section dependence in panels. Discussion Paper No. 1240, University of Cambridge.

Phillips, P. C. B., \& Perron, P. (1988). Testing for a unit root in time series regression. Biometrika, 75(2), 335-346.

Reis, L., Meuer, R., \& Da Silva, S. (2010). Stock returns and foreign investment in Brazil. Applied Financial Economics, 20, 1351-1361.

Richards, A. (2005). Big fish in small ponds: The trading behavior and price impact of foreign investors in Asian emerging equity markets. Journal of Financial and Quantitative Analysis, 40(1), 1-27.

Samarakoon, L. P. (2009). The relation between trades of domestic and foreign investors and stock returns in Sri Lanka. Int. Fin. Markets, Ins. and Money, 19, 850-861.

Swanson, P. E., \& Lin, A. Y. (2003). The role of U.S. investors in international equity market inflows, outflows, and net flows for selected emerging Asian markets. Journal of Economics and Finance, 27(3), 300-320.

Topaloğlu, E. E. (2018). Bankalarda finansal kırılganlığı etkileyen faktörlerin panel veri analizi ile belirlenmesi. Eskişehir Osmangazi Üniversitesi IiBF Dergisi, 13(1), 15-38.

Travlos, N., Trigeorgis, L., \& Vafeas, N. (2001). Shareholder wealth effects of dividend policy changes in an emergingstock market: The case of Cyprus. Multinational Finance Journal, 5, 87-112. 

Analizi

Yıldız, Y. (2017). Yabancı sermaye ve hisse senedi getiri oynaklı̆̆ı: Borsa İstanbul üzerine bir inceleme. İ̧̧letme Araştırmaları Dergisi, 9(4), 17-32.

Warther, V. A. (1995). Aggregate mutual fund flows and security returns. Journal of Financial Economics, 39(2-3), 209235.

Wooldridge, J. M. (2002). Econometric analysis of cross section and panel data. Cambridge: The MIT Press.

WFE, (2018). What attracts international investors to emerging markets? https://www.world-exchanges.org/ourwork/articles/what-attracts-international-investors-emerging-markets 


\section{Ekler}

Ek 1. Birim Kök Testine Iliş̧kin Özet Sonuçlar

Grup Birim Kök Testi: Özet

Örneklem: 32

Bireysel Etkiler

\begin{tabular}{|c|c|c|c|c|c|c|c|c|}
\hline \multirow{11}{*}{ Yöntem } & \multirow{11}{*}{$\begin{array}{l}\text { Birim } \\
\text { Sayısı }\end{array}$} & \multirow{11}{*}{$\begin{array}{c}\text { Gözlem } \\
\text { Sayısı }\end{array}$} & \multicolumn{3}{|c|}{ Seriler } & & & \\
\hline & & & \multicolumn{2}{|c|}{ AR1 } & \multicolumn{2}{|c|}{ OVOL1 } & & \\
\hline & & & \multicolumn{2}{|c|}{ AR2 } & \multicolumn{2}{|c|}{ OVOL2 } & & \\
\hline & & & \multicolumn{2}{|c|}{ AR3 } & \multicolumn{2}{|c|}{ OVOL3 } & \multicolumn{2}{|c|}{ LOGOSOZ1 LOGOSOZ2 } \\
\hline & & & \multicolumn{2}{|c|}{ AR4 } & \multicolumn{2}{|c|}{ OVOL4 } & \multicolumn{2}{|c|}{ LOGOSOZ3 LOGOSOZ4 } \\
\hline & & & \multicolumn{2}{|c|}{ AR5 } & \multicolumn{2}{|c|}{ OVOL5 } & \multicolumn{2}{|c|}{ LOGOSOZ5 LOGOSOZ6 } \\
\hline & & & \multicolumn{2}{|c|}{ AR6 } & \multicolumn{2}{|c|}{ OVOL6 } & \multicolumn{2}{|c|}{ LOGOSOZ7 LOGOSOZ8 } \\
\hline & & & \multicolumn{2}{|c|}{$\begin{array}{l}\text { AR7 } \\
\text { AR8 }\end{array}$} & \multicolumn{2}{|c|}{ OVOL7 } & \multicolumn{2}{|c|}{ YOYD } \\
\hline & & & \multirow{2}{*}{\multicolumn{2}{|c|}{ YOYD }} & \multirow{2}{*}{\multicolumn{2}{|c|}{$\begin{array}{l}\text { OVOL8 } \\
\text { YOYD }\end{array}$}} & & \\
\hline & & & & & & & & \\
\hline & & & İstatistik & Prob. & İstatistik & Prob. & İstatistik & Prob. \\
\hline Levin, Lin \& Chu & 9 & 277 & $-14,2500$ & 0,0000 & $-14,2839$ & 0,0000 & $-9,67417$ & 0,0000 \\
\hline Im, Pesaran, Shin & 9 & 277 & $-13,3005$ & 0,0000 & $-12,8285$ & 0,0000 & $-8,70665$ & 0,0000 \\
\hline ADF- Fisher Chi-square & 9 & 277 & 170,700 & 0,0000 & 163,195 & 0,0000 & 104,658 & 0,0000 \\
\hline PP-Fisher Chi-Square & 9 & 279 & 194,032 & 0,0000 & 179,547 & 0,0000 & 120,326 & 0,0000 \\
\hline
\end{tabular}

Ek 2. Hausman Testine Illişkin Özet Bilgiler

\begin{tabular}{|c|c|c|c|c|c|}
\hline $\begin{array}{l}\text { Bağımlı } \\
\text { Değişken }\end{array}$ & Bağımsız Değişken & Chi-Sq. İstatistiği & Chi-Sq. d.f. & Prob,* & $\begin{array}{c}\text { Rassal } \\
\text { Etki }\end{array}$ \\
\hline AR1 & YOYD & 0,195 & 1 & 0,6586 & Kabul \\
\hline AR2 & YOYD & 8,012 & 1 & 0,0046 & Red \\
\hline AR3 & YOYD & 8,408 & 1 & 0,0037 & Red \\
\hline AR4 & YOYD & 0,361 & 1 & 0,5477 & Kabul \\
\hline AR5 & YOYD & 0,124 & 1 & 0,7246 & Kabul \\
\hline AR6 & YOYD & 0,026 & 1 & 0,8699 & Kabul \\
\hline AR7 & YOYD & 0,012 & 1 & 0,9125 & Kabul \\
\hline AR8 & YOYD & 0,332 & 1 & 0,5644 & Kabul \\
\hline OVOL1 & YOYD & 0,601 & 1 & 0,438 & Kabul \\
\hline OVOL2 & YOYD & 2,697 & 1 & 0,1005 & Kabul \\
\hline OVOL3 & YOYD & 13,715 & 1 & 0,0002 & Red \\
\hline OVOL4 & YOYD & 10.986 & 1 & 0,0009 & Red \\
\hline OVOL5 & YOYD & 7.787 & 1 & 0,0053 & Red \\
\hline OVOL6 & YOYD & 2.026 & 1 & 0,1545 & Kabul \\
\hline OVOL7 & YOYD & 0,006 & 1 & 0,9347 & Kabul \\
\hline OVOL8 & YOYD & 0,082 & 1 & 0,7739 & Kabul \\
\hline LOGOSOZ1 & YOYD & 3.555 & 1 & 0,0594 & Kabul \\
\hline LOGOSOZ2 & YOYD & 3,609 & 1 & 0,0575 & Kabul \\
\hline LOGOSOZ3 & YOYD & 6,078 & 1 & 0,0137 & Red \\
\hline LOGOSOZ4 & YOYD & 9,310 & 1 & 0,0023 & Red \\
\hline LOGOSOZ5 & YOYD & 8,031 & 1 & 0,0046 & Red \\
\hline LOGOSOZ6 & YOYD & 4,270 & 1 & 0,0388 & Red \\
\hline LOGOSOZ7 & YOYD & 1,943 & 1 & 0,1633 & Kabul \\
\hline LOGOSOZ8 & YOYD & 3,618 & 1 & 0,0571 & Kabul \\
\hline
\end{tabular}


This Page Intentionally Left Blank 